\title{
Manoel Gonçalves Ferreira Filho Diretor da Faculdade de Direito
}

\section{A Redação}

O Professor Doutor Manoel Gonçalves Ferreira Filho, novo Diretor da Faculdade de Direito, é filho do Dr. Manoel Gonçalves Ferreira e Dona Elsy Moraes Ferreira; nasceu nesta Capital aos 21 de junho de 1934. Casou-se em 1958 com a Dra. Ivete Senise Ferreira.

$\mathrm{Fez}$ os estudos primários no Externato "Assis Pacheco" e os secundários no "Colégio São Luís" desta Capital.

Em 1953 ingressa na Faculdade de Direito da Universidade de São Paulo, colando grau de Bacharel em Ciências Jurídicas e Sociais em 1957 após brilhante currículo.

Fazendo o curso de doutoramento na Universidade de París, recebe o Título de Doutor em maio de 1960 com menção "Très Bien".

Desde 1965, é livre-docente de Direito Constitucional e lecionou essa matéria, como regente, nesta Faculdade e na Faculdade Paulista de Direito da Pontifícia Universidade Católica; regeu também nesta Faculdade a Cátedra de Direito Internacional Privado e, na Universidade Católica, a Cátedra de Introdução à Ciência do Direito da qual é Professor Assistente.

Na Faculdade de Filosofia, Ciências e Letras de São Bento, da Pontifícia Universidade, onde coordenou o curso de Ciências Sociais, e na de Ciências e Letras da Universidade Católica de Campinas regeu as Cátedras de História das Idéias Políticas e Política, respectivamente.

O novo diretor da Faculdade de Direito exerce a advocacia desde 1960 e foi assessor Jurídico do Secretário 
da Fazenda do Estado de São Paulo em 1969. Integra a Ordem dos Advogados do Brasil, a Associação dos Advogados de São Paulo, da qual foi conselheiro de 1967 a 1969 e o Instituto dos Advogados de São Paulo desde 1967.

Participou ativamente de comissões encarregadas de elaborar vários anteprojetos: 0 anteprojeto da Constituição do Estado em 1967, o anteprojeto do Código Tributário do Estado de São Paulo em 1969, e o anteprojeto de emenda à Constituição do Estado em 1969. Participou, também, da mesa Redonda sobre "Sufrágio Distrital" na Fundação Getúlio Vargas do Rio de Janeiro, em 1971.

Com a tese Do Processo Legislativo, o Professor Ferreira Filho concorreu à Cátedra de Direito Constitucional desta Faculdade. Classificado em $1 .^{\circ}$ lugar, entre outros notáveis candidatos, é nomeado em 25 de setembro de 1969 e toma posse da Cátedra a 13 de outubro do mesmo ano, sucedendo o Professor Doutor Cândido Motta Filho.

Ao assumir a titularidade de Direito Constitucional nesta Faculdade, em 1969, o Professor Manoel Gonçalves Ferreira Filho dizia em seu discurso de posse: "Chegamos no bom momento, já a Faculdade revela, mesmo a quem só enxergar o aspecto exterior, a chegada de nova primavera", e mais adiante, referindo-se à reforma do ensino jurídico, "não venho propô-la venho servi-la".

Sua Excelência vinha, realmente, propô-la e servi-la ao mesmo tempo na qualidade de diretor desta Faculdade e chegava no "bom momento" para dar sua contribuição não somente ao ensino jurídico mas às altas esferas administrativas, para as quais foi logo convocado: em 1969 1970 para a chefia do Gabinete do Ministério da Justiça; de 1969 a 1971 para a Secretaria do Conselho de defesa dos Direitos da Pessoa Humana; de 1970 a 1971 na Secretaria Geral do Ministério da Justiça e, interinamente ao assumir o Ministério da Justiça, em 1970.

No âmbito universitário é eleito, em 1971, chefe do Departamento de Direito do Estado, cargo exercido até 


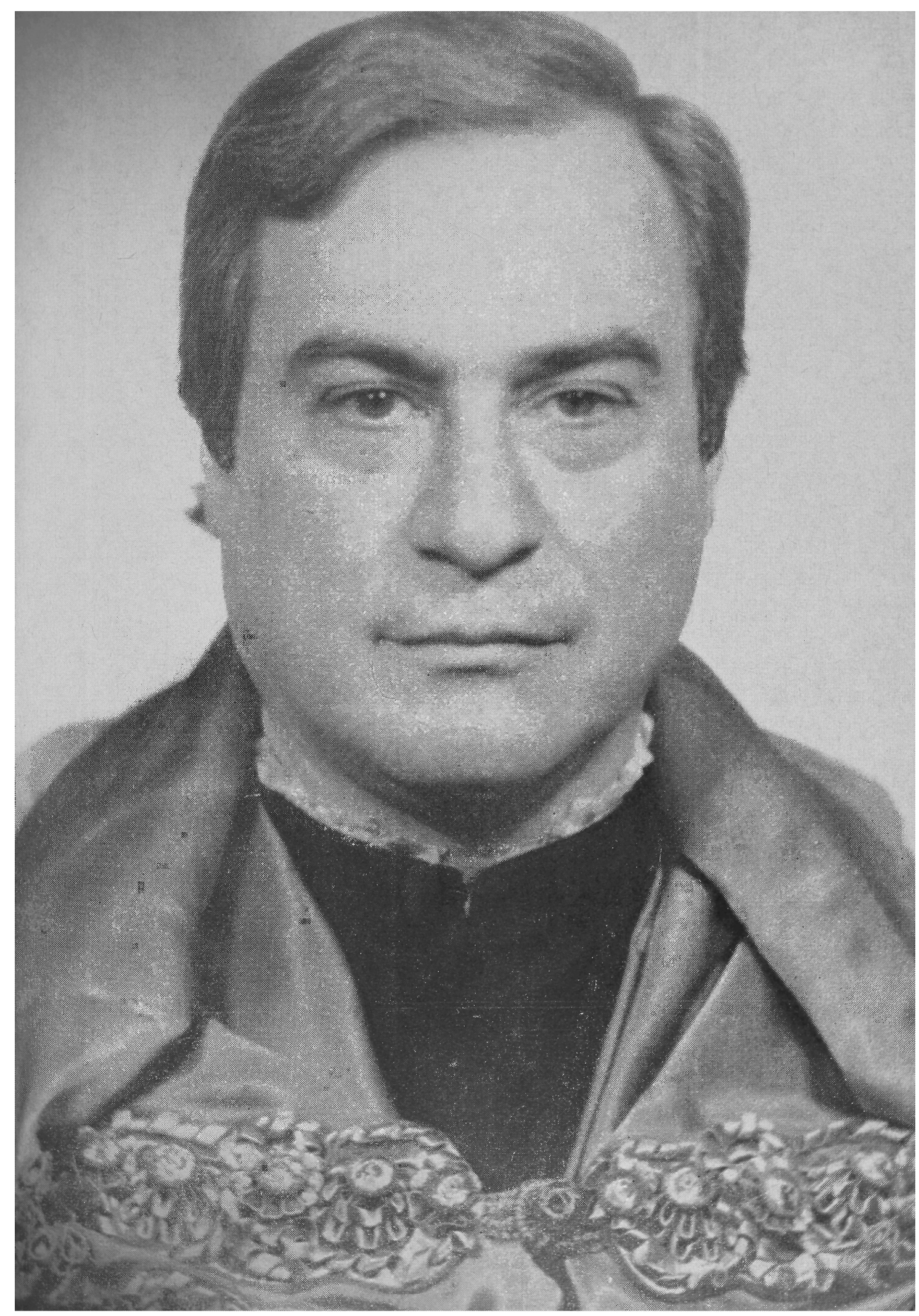


Professor "Dr. Manoel Gonçalves Ferreira Filho, Diretor da Faculdade de Direito. 
novembro de 1973, quando, por maioria de votos, é indicado pela Congregação de Professores e escolhido pelo Magnífico Reitor para suceder o Prof. José Pinto Antunes na diretoria da Faculdade.

No exercício dos altos cargos administrativos ou docentes imprime a marca de sua personalidade justa, enérgica, dinâmica, criadora, e luminosa cultura.

Quando Secretário Geral da Justiça lança a idéia da criação do Instituto de Direito Político; no cargo de Secretário do Conselho de Defesa dos Direitos da Pessoa Humana (1969 - 1971) em discurso pronunciado no auditório do Ministério da Educação, sob o título Democracia $e$ Direitos do Homem, expõe suas idéias políticas a respeito dos direitos do homem, de sua liberdade e dignidade aliadas à democracia.

Em missão oficial do governo brasileiro visita a França a República Federal Alemã e a Grã-Bretanha, em maio de 1970, e em novembro do mesmo ano os Estados Unidos e a Itália.

Em 1971, faz o curso na Escola Superior de Guerra, proferindo em agosto de 1973, na mesma escola, uma conferência sob o título Poder Executivo.

Na chefia do departamento de Direito do Estado, desta Faculdade cria e ministra, em 1973, uma nova disciplina; "Liberdades Públicas", despertando grande interesse dos estudantes do curso de pós-Graduação, inclusive de outros professores que passaram a freqüentá-la.

\section{Bibliografia.}

O professor Dr. Manoel Gonçalves Ferreira Filho publicou livros, artigos e conferências versando o tema de sua especialidade, Direito Constitucional. É de notar-se que a maior parte da bibliografia desenvolveu-se no espaço de quatro anos, i. e., de 1969 a 1973, após a titula- 
ridade de Direito Constitucional, documentando a constante evolução científica de sua obra. Foram publicados de 1960 a 1973 os seguintes trabalhos:

\section{Livros.}

1. Le Statut Constitutionnel des Partis Politiques au Brésil, en Italie, en Allemagne et en France, Paris, 1960.

2. O Estado de Sitio, S. Paulo, 1964.

3. Os Partidos Políticos nas Constituições Democráticas, Belo Horizonte, 1966.

4. Curso de Direito Constitucional, S. Paulo, - Saraiva, 1. ${ }^{\text {a ed., }}$ 1967; 2. ${ }^{\mathrm{a}}$ ed., 1970, 3. ${ }^{\mathrm{a}}$ ed., 1971; 4. ${ }^{\mathrm{a}}$ ed., 1973.

5. Do Processo Legislativo, S. Paulo, Saraiva, 1968.

6. A Democracia Possivel, S. Paulo, Saraiva, 1972.

7. Comentários à Constituição Brasileira, I Volume - II volume 1974.

\section{Artigos e Conferências Publicadas.}

1. Parlamentarismo, Presidencialismo, Sistema Eleitoral e Sistema de Partidos, em Forum, 1962.

2. Aspectos politicos do Confronto Parlamentarismo versus Presidencialismo, em Sociologia, Setembro de 1962.

3. Democracia e Desenvolvimento. Econômico, em Rev. da Universidade Católica de Campinas, dezembro de 1963 e Rev. da Universidade Católica de São Paulo. Junho de 1963.

4. Democracia, Organização Política e Regime de Governo, em Rev. da Universidade Católica de 'São Paulo, julho-dezembro de 1964.

5. A Extensão do Poder Regulamentar na Constituiç̃̃o Francesa de 1958, em Justitia, vol. 51, 1965 e RDA, vol. 84, 1966.

6. Paz, Tensões e Desenvolvimento, em Convivium, n. 5, S. Paulo, 1968.

7. Notas para a Sistemática do Ato Complementar, em Rev. de Direito Público, S. Paulo, vol. 8, 1969.

8. Le Véto Partiel en Droit Constitutionnel Brésilien, em Prespectivas del Derecho Público en la Segunda Mitad del siglo XX, IEAL, Madrid, 1969, tomo III.

9. Democracia e Direitos do Homem, Boletim n. 1 - do Conselho de Defesa dos Direitos da Pessoa Humana, Rio de Janeiro, 1969. 
10. Democracia: Formação e Informação Política, Ministério da Justiça, Rio de Janeiro, 1970.

11. Fidelidade Partidária e Voto Distrital, em O Estado de S. Paulo, março de 1971.

12. O Sufrágio distrital e a Reforma Política, em O Estado de S. Paulo, agosto de 1971.

13. O Poder Democrático, em Convivium, setembro-outubro de 1971.

14. Institucionalização política do Processo Revolucionário, em em Convivium, Janeiro-fevereiro de 1972.

15. O Modelo político na Constituição Vigente, em LTR, abril de 1972.

16. O Veto parcial no Direito. Brasileiro, em Rev. de Direito Público, n. 17, 1972.

17. O Processo Legislativo e sua Missão, conferência realizada na Câmara Municipal de Ribeirão Preto, em maio de 1973.

18. O Poder Executivo, conferência realizada na Escola Superior de Guerra, em agosto de 1973.

19. Ruy o Constitucionalista, conferência realizada na Faculdade de Direito da Universidade de São Paulo, em março de 1973.

\section{O Novo Diretor Assume o Cargo.}

Em 30 de novembro do corrente ano, reuniu-se a Congregação de Professores em sessão solene, presidida pelo Magnífico Reitor da USP, professor Orlando Marques de Paiva, para investir no cargo o novo diretor.

Compareceram à cerimônia inúmeras autoridades, entre as quais o Dr. Waldemar Mariz de Oliveira Júnior, Secretário da Justiça, representando sua Excelência o Sr. Governador do Estado, Laudo Natel; senador André Franco Montoro; desembargador Marrey Júnior, presidente do Tribunal Eleitoral de São Paulo; desembargador Italo Galli, presidente do Tribunal de Alçada Criminal de São Paulo, professor Arrobas Martins, ex-secretário da Fazenda, além de grande número de convidados e alunos que lotavam inteiramente o salão nobre. 
Introduzido no doutoral pelos professores José Pinto Antunes, que deixava a diretoria, Moacyr Amaral Santos, e Washington de Barros Monteiro, sua excelência presta o compromisso de praxe e recebe a saudação de seus pares através palavras do Professor Dr. Oscar Barreto Filho, que analisa a obra do novo diretor e exalta-lhe as qualidades de professor, de jurista e de administrador.

\section{Discurso de saudação do Professor Oscar Barreto Filho.}

Hoje é dia de festa. Engalana-se e atavia-se a velha Academia, cellula mater do ensino jurídico no Brasil, para receber de braços abertos o filho bem-amado, ora investido nas altas funções de Diretor.

Jovem ainda, pleno de entusiasmo e de esperança, assume o Professor Manoel Gonçalves Ferreira Filho a responsabilidade do governo desta Casa, galardão a que faz jus não só pelo seu inconteste valor moral e intelectual, como ainda pela confiança de seus pares e a estima em que é tido pelos inumeráveis discípulos.

Só há motivo para ufania pela acertada escolha de nosso novo dirigente, cujo mérito intelectual, demonstrado em memoráveis prélios universitários, melhor, se apurou no exercício de elevados cargos da administração pública.

Bem vale relembrar, em rápida pinceladas, o brilhante currículo com que o Professor Manoel Gonçalves Ferreira Filho se apresenta à admiração de seus concidadãos.

Ingressando nesta querida Faculdade em 1953, aqui hauriu os princípios fundamentais da ciência jurídica, desde cedo evidenciando seu pendor pelas matérias de Direito Público, sob a lúcida orientação de mestres do porte de Ataliba Nogueira, Candido Mota Filho e Mário Masagão.

Formado bacharel em Ciências Jurídicas e Sociais, em 1957, vêmo-lo a seguir rumando para a França, a fim 
de fazer o curso de doutoramento na Universidade de Paris. Lá se dedica, durante dois anos, com acendrado fervor, ao cultivo das matérias de sua predileção.

No velho edifício da Place du Panthéon, segue sucessivamente os cursos de pós-graduação de M. Maurice Duverger, sobre Ciência Política; M. ANdré Hauriou, sobre Direito Público Geral; M. Jean - JAcques Chevallier, sobre História das Idéias Políticas; M. Paul Bastid, sobre Direito Direito Constitucional Comparado. Trabalhando sob a orientação do Professor Georges Vedel, elabora tese de Direito Constitucional acerca de Os Partidos Políticos nas Constituições Democráticas, na sustentação da qual obtém o grau de doutor, em maio de 1960 , com a menção "très bien".

Como bom jurista, já que o Direito nasce do coração dos homens, não se esqueceu o nosso homenageado de temperar os rigores do estudo com a suave companhia de sua encantadora esposa Yvette, com quem partilhou as agradáveis tardes parisienses, ao longo dos "quais" e "boulevards"...

Regressando ao Brasil, iniciou Manoel Gonçalves Ferreira sua carreira docente, aliando à ciência dos livros a experiência didática. Ei-lo, em 1965, livre-docente de Direito Constitucional, com a tese $O$ Estado de Sítio. Desde então, ininterruptamente, lecionou esta matéria, como regente, nesta Faculdade e na Faculdade Paulista de Direito, da Pontifícia Universidade Católica. Regeu, ainda, nesta Escola, a cátedra de Direito Internacional Privado e, na Universidade Católica, a disciplina de Introdução à Ciência do Direito.

Na Faculdade de Filosofia, Ciências e Letras de São Bento, onde coordenou o curso de Ciências Sociais, e na Faculdade de Ciências e Letras da Universidade Católica de Campinas, regeu as disciplinas de História das Idéias Políticas e Política, respectivamente. 
Membro ilustre de vários institutos de estudos juridicos, integrou ainda a Comissão incumbida de promover a adaptação da Constituição do Estado à nova Constituição do Brasil.

Pesquisador de fôlego, dedicou-se à análise dos problemas cruciais do momento político, publicando vários trabalhos doutrinários em que versou temas como o parlamentarismo e presidencialismo, o poder regulamentar, a sistemática do ato complementar, democracia e desenvolvimento econômico, sistemas eleitorais e estruturas partidárias, e outros que tais.

Em 1967, como fruto sumarento da experiência de vários anos de ensino, apresenta o jovem mestre a síntese do seu pensamento em um livro de texto simples e claro, límpido e conciso, no qual traça o roteiro seguro e atualizado do Direito Constitucional moderno.

Vagando-se a cátedra de Direito Constitucional em 1969, em decorrência da jubilação do Professor Candido Mota Filho, a ela concorrem quatro livres-docentes da Casa, em torneio magnífico, que marcou época na vida juridica e universitária, no qual, como já se disse alhures, engrandecidos e dignificados, cada vez mais respeitados, sairam os que nele tomaram parte.

Sagrou-se vencedor o Professor Manoel Gonçalves Ferreira, com sua preciosa tese Do Processo Legislativo, ensaio crítico de Direito Constitucional Comparado, tendo em vista, especialmente, o modelo constitucional brasileiro. Neste trabalho, firma o autor sua reputação come constitucionalista, trazendo uma excelente contribuição para o estudo da lei, como expressão da vontade geral e ảa vontade política, e de suas funções no regime democrático.

Andou bem o Professor Manoel em cedo publicar a seu Curso de Direito Constitucional. Na nota preliminar do livro, como que prevê a própria trajetória, ao observar que os juristas brasileiros, "quando consentem em elabo- 
rar livros de ensino, não os podem levar a cabo, chamados pelo país a tarefa mais altas. E esse apelo afasta particularmente os constitucionalistas de seus gabinetes porque, afeitos como são por ofício aos problemas políticos, deles se esperam freqüentemente soluções para os problemas fundamentais da nação".

$\mathrm{E}$ foi exatamente isto o que sucedeu. Houve por bem o alto Governo da República em convocar o teórico de A Democracia Possível, para que colaborasse na realização prática dos valores fundamentais da democracia em nosso país. Acedendo ao convite, exerceu os cargos de chefe do gabinete do Ministro da Justiça (de 1969 a 1970); secretário do Conselho de Defesa dos Direitos da Pessoa Humana (de 1969 a 1971); secretário-geral do Ministério da Justiça (de 1970 a 1971); e Ministro interino da Justiça (em setembro de 1970).

Reiniciadas as atividades docentes, nosso Professor vem demonstrando seu empenho na renovação dos métodos do ensino jurídico, com a adoção de processos didáticos - mais consentâneos com os novos tempos. Conta, para tanto, com a melhoria das condições materiais propiciada pelo esforço sem par e pela dedicação incansável dessa notável figura de humanista e de administrador que é o Professor José Pinto Antunes. Por outro lado, a criação dos Departamentos, a modificação da estrutura curricular e a implantação dos cursos de mestrado e doutorado são hoje fatos consumados. Ao novo Diretor, cumpre tão-somente prosseguir na luminosa senda traçada por seus ilustres antecessores.

Como mestre de Direito Constitucional, não podia Manoel Gonçalves Ferreira Filho afastar de suas cogitacõ̃es e temática da liberdade e da democracia. E lembra, que a democracia só pode vicejar num meio em que não faleçam condições mínimas de desenvolvimento cultural, econômico e social. Daí a necessidade de adequar as instituições políticas nacionais à realidade econômico-social, 
tendo em vista, principalmente, a tensão gerada pelo desenvolvimento econômico.

Esta sua preocupação constante se revela a cada passo, no trato dos problemas políticos e universitários. Ainda agora, ao ser estruturado o ciclo de especialização, sugere a inclusão, entre as matérias que irão integrar a área do Direito do Estado, da disciplina Liberdades Públicas, a exemplo da Faculdade de Direito de Paris. Como observa Duverger, a democracia é um regime para "povos maiores". E preciso educar, para a plena fruição da liberdade. Essa é a missão da Universidade, essa é a tarefa do professor de Direito.

Não se equivocava o eminente Professor Washington de Barros Monteiro, quando, em outubro de 1969, ao saudar o novel catedrático de Direito Constitucional, congratulava-se com os circunstantes, dizendo: "feliz esta Faculdade, por contar com um professor como Manoel Gonçalves Ferreira Filho, animado sempre do mais alto senso do dever e que, em todos os lances de sua existência, tem imprimido a mais aguda exação no cumprimento de suas obrigações".

Realmente, os sinais marcante da personalidade do novo Diretor, sua vasta e profunda cultura jurídica, sua aprimorada formação humanista, seu senso pragmático, sua integridade, sua facilidade de comunicação, constituem o penhor seguro do êxito de sua administração, em benefício da mocidade acadêmica e da grandeza da Universidade e da Pátria.

Senhor Professor Manoel Gonçalves Ferreira Filho: Ressaltou V. Excia., na sua oração de posse na cátedra, o fato de que fora impelido até aqui por dois gigantes: o Amor e a Amizade. Esse Amor e essa Amizade, encontrados nos bancos e nas Arcadas desta Escola, continuarão por certo a apoiá-lo e a estimulá-lo, para que todos os ideais que animam o nobre espírito de V. Excia. se convertam. em realidade. 
Para isso, conta V. Excia. com tudo: a versatilidade da inteligência, a determinação da vontade e o requinte da sensibilidade. E, também, com a compreensão e o carinho da companheira eleita por seu coração e de suas quatro graciosas filhas, a amizade e a cooperação de seus colegas, o respeito e a afeição de seus incontáveis alunos.

Mãos à obra e felicidades, meu caro Diretor.

\section{Discurso de Posse do Novo Diretor.}

Após as palavras do representante da Congregação, o novo diretor é saudado pelo acadêmico Luís Antônio Alves de Souza em nome do corpo discente; em seguida profere seu discurso de posse em que salienta pontos dominantes de sua doutrina, o reconhecimento dos direitos do homem, à sua liberdade, à sua dignidade, à justiça. Referiu-se também à necessidade de renovação do ensino jurídico e da especialização para que a tradição jurídica da Academia se ajuste às mudanças sociais e à evolução do Direito. Filho.

A seguir, discurso do Prof. Manoel Gonçalves Ferreira

"Há vinte anos, poucos dias mais, penetrava eu, pela primeira vez, o recinto sagrado da Academia. Era, então calouro. Vinha emocionado e assustado. A emoção advinha de passar ao rol dos acadêmicos do Largo de São Francisco. Era por ser, de algum modo, colega de escola de Rui, de Nabuco, de Castro Alves, de Fagundes Varela e de tantos outros. O temor provinha do "trote" com que os veteranos saudavam, entre cruéis e jocoso, os novos estudantes que cumpria despertar para a realidade.

"Hoje, penetro, mais uma vez, as Arcadas. Piso-lhe os caminhos como centenas, milhares de vezes já o fiz desde aquele primeiro dia. Não me acompanha mais o receio que os fios brancos de há muito afugentaram. Não mais me esperam, sedentos de sangue como risonhamente 
afirmavam, veteranos que faziam da tesoura a arma adequada para corrigir a empáfia do primeiro-anista. Do novel estudante de Direito do Largo de São Francisco.

"A emoção, porém, me acompanha, palpável, quase opressiva. O coração bate acelerado, a voz se embarga, os olhos marejam. A cada passo que dou pelos corredores da casa ouço uma voz, sinto um olhar, percebo uma presença. São os grandes do passado, os mestres e os discípulos que fizeram a história da Academia a me medirem, a me exortarem a não desmerecer as glórias da Casa.

"Neste salão nobre, a emoção ainda cresce. Nele está o presente da Academia. Os grandes mestres de hoje que todos seriam mais dignos do que eu de assumir a direção da Facúldade. Os estudantes de 1973 que conservam bem viva a Escola, aptos a renovar, a qualquer instante, os triunfos da Academia. E particularmente a figura do Prof. Pinto Antunes, diretor a quem sucedo mas com quem, certamente, não me poderei ombrear.

"Foi neste mesmo salão nobre, Professor Pinto Antunes, que vos vi pela primeira vez. Era a ocasião do concurso para a cátedra de Economia Política. Muitos eram os candidatos, alguns dos quais expoentes do pensamento nacional. Ilustre era a banca examinadora, como sempre resumindo o que de melhor havia no corpo docente das Faculdades brasileiras. Foi a ocasião de Vossa vitória, fruto do saber acumulado pelo estudo desvelado, da agilidade de Vossa inteligência, da habilidade de vossa argumentação.

"Foi neste mesmo salão, Professor Pinto Antunes, que pela primeira vez me defrontei convosco. Era eu candidato à docência e vos encontrava, agudo e seguro, entre os componentes da banca. Podia ter sido sepultado pela crítica, fui estimulado pela vossa generosidade.

"Igualmente, neste salão, já titular de Direito Constitucional, assisti à vossa posse como diretor da Faculdade. Assumieis o posto num momento difícil. A Escola ainda 
trazia no corpo as feridas e cicatrizes da luta política. O pior, entretanto, não era isso. Entre estudantes e professores pareciam rompidas as pontes, não havia diálogo possível.

"Quatro anos depois, Professor Pinto Antunes, eu vos sucedo na diretoria. Bem diferente é o quadro. Nova primavera floresce na Academia. Còm desvelo e carinho, com fino gosto e dedicação, foi renovado o imóvel. É, sem dúvida, a mais bela e rica das Faculdades brasileiras.

"Mas, eminente Professor, não é esse, nem de longe, o vosso mais lídimo título de glória. O mérito que acumulastes como diretor não provém do arranjo bem feito das coisas materiais, resulta do relacionamento humano que soubestes encetar. Não temestes os alunos. Soubestes ouvir-lhes as reivindicações, apoiá-las quando justas. Restabelecestes, com isso, o diálogo entre mestres e discípulos. Fizestes de novo da Academia um só corpo, uma só alma. Isso ninguém esquecerá, nem estudantes nem professores. Isso todos vos agradecem, do fundo d'alma.

"Recebe, por isso, o novo diretor uma Faculdade reconciliada com suas tradições, pronta a repetir, para o bem do Brasil, os seus feitos passados.

“A Academia do Largo de São Francisco, nos seus quase cento e cinqüenta anos de vida, pode jactar-se de suas tradições. Não é isso louvor em boca própria, nem arroubo de oratória. É o que ensina a história do Brasil. Nenhuma das grandes causas da nacionalidade deixou de encontrar ressonância nas Arcadas, deixou de inscrever na sua vanguarda os bacharéis e os estudantes do Largo de São Francisco.

"Dessas tradições duas ressaltam interpenetradas: a tradição jurídica e a tradição política.

“A tradição jurídica é, de certa forma, conseqüência inexorável de uma Faculdade de escol. Sábios juristas sempre enriqueceram as suas cátedras, não menos sábios discípulos puseram em prática, nas lutas do Foro, os ensina- 
mentos recebidos. Na formulação do pensamento jurídico brasileiro, no seu acrisolamento, na prática diuturna, os graduados do Largo de São Francisco sempre ocuparam como ainda ocupam o primeiro plano. Baldado é citar nomes. Entretanto, e aqui está o ponto crucial, a tradição juridica da Academia não se esgota no campo restrito das formulações doutrinárias ou da prática forense. Ela vai muito além.

“De fato, a primeira tradição jurídica da Faculdade do Largo de São Francisco é a dedicação aos direitos do homem, à liberdade. $O$ direito que aqui se aprende não é a norma fria, capaz de traduzir qualquer conteúdo. Não é a lei formal, que pode ser instrumento de opressão. É o direito inspirado na Justiça, o direito alicerçado no reconhecimento da liberdade e da dignidade humanas.

“Dois episódios históricos ilustram essa verdade.

"Um que marcou profundamente a Academia ainda jovem foi a Abolição. Ora, o que foi essa batalha se não uma campanha intimorata pela liberdade e pela dignidade humanas, condições indispensáveis da grandeza nacional? Quem não se lembra dos versos célebres com que um acadêmico do Largo de São Francisco vinculou à bandeira da Pátria a causa da liberdade:
"Auriverde pendão de minha terra, Que a brisa do Brasil beija a balança, Estandarte que a luz do sol encerra, $\mathrm{E}$ as promessas divinas da esperança... Tu, que da liberdade após guerra, Foste hasteado dos heróis na lança, Antes te houvessem roto na batalha, Que servires a um povo de mortalha!"

“Outro, já centenária a Academia, veio encontrá-la, de pé, unida, corajosa. É o combate pela Constituição. É 1932! 
"1932 é uma data de história do Brasil, da história de São Paulo mas também dos anais do Largo de São Francisco. Nesta casa de leis, votada a liberdade, nasceu e reboou a causa da Constituição. Não a Constituição pela Constituição, não qualquer Constituição, mas uma Constituição capaz de garantir os direitos do homem, de propiciar a democracia.

"Naquele momento, mestres e discípulos, em uníssino se dispuseram à luta, porque, como diz a trova acadêmica:

"Quando se sente bater

No peito heróica pancada

Deixa-se a folha dobrada

Enquanto se vai morrer".

"A tradição jurídica do Largo de São Francisco se transmuda, pois, insensivelmente na sua tradição política. A Academia nunca foi apenas uma escola de direito, sempre foi também uma escola de estadistas. Não é por mera coincidência que onze presidentes da República estudaram em seus bancos, respiraram o seu ar, viveram, no instante decisivo da formação, o seu ambiente de tradição e progresso. De progresso, sim.

"Realmente, a tradição no Largo de São Francisco não se confunde com o culto do passado. Como São Paulo, a Academia não sabe parar. Os louros do passado espicaçam-na em busca de novas metas, de novas glórias. Não existe aqui lugar para o saudosismo.

"Com efeito, o peso das tradições esmagaria quem permanecesse estático pretendendo apenas mantê-las de pé, como objeto de culto. Ao contrário, para quem quer progredir são elas fonte de impulso, de aceleração no plano inclinado do porvir.

“Por isso, a Faculdade haverá de estar sempre na vanguarda da renovação jurídica e política brasileiras. 
“A tradição jurídica somente permanecerá viva, na medida em que palpitar na renovação da ciência do direito e do estudo do direito.

"O direito busca impor a Justiça na vida social. Se, portanto, seus valores, os valores da Justiça, são eternos, os seus instrumentos, as leis, devem ter presente a realidade presente e não passada. Ora, a mudança acelerada das estruturas sociais reclama que, a cada dia, o direito seja repensado, que ,a todo instante, as soluções consagradas sejam revistas. Sem dúvida, isso não é fácil para o jurista, acostumado a aguardar que o tumulto das revoluções se aplaque, para depois erguer sua obra.

"Entretanto, quando o jurista se torna caudatário das mudanças, quando estas se fazem sem ele, as forças sociais perdem o rumo da Justiça. Tornam-se cegas e descontroladas. Não logram concluir jamais sua obra. Não atingem a paz, pois que esta é fruto da Justiça.

"Uma Faculdade de Direito é um centro de estudos e pesquisas em prol da Justiça. A primeira tarefa, pois, em que a Academia há de empenhar-se, como sempre empenhou, é na procura de fórmulas jurídicas adequadas ao tempo que corre. Só assim poderá a comunidade alcançar os objetivos de Justiça, na paz e na liberdade.

"Mas uma Faculdade não é apenas um centro de saber, é igualmente um núcleo de formação. É cediço reconhecer que nela se há de propiciar a formação profissional, habilitando o estudante, a mais tarde, exercer as nobres funções do advogado, do juiz, do promotor, do consultor jurídico de empresa ou da administração pública.

"Disso não descurou jamais a Academia que agora se empenhará numa renovação de métodos e caminhos. De fato, o novo currículo da Faculdade que teve por relator o eminente Professor Oscar Barreto Filho, cuja saudação generosa de há pouco demonstrou que tem o coração tão grande quanto privilegiado o cérebro, se preocupa não só 
com a formação do homem de leis, mas também com sua especialização.

"Realmente, nos dois últimos semestres do Curso, o aluno que já recebeu uma sólida formação básica, vai seguir os cursos de uma especialidade, segundo sua escolha. $O$ século $\mathrm{XX}$ não mais comporta o graduado que de tudo sabe um pouco e somente pouco. Exige que ele de tudo conheça o mínimo mas de alguma coisa saiba muito. mente que visa a especialização que, inovando, sendo a primeira entre todas as escolas brasileiras, a Academia implantará em 1974.

“Essa especialização não importará em abandono do programa de pós graduação que já se desenvolve, com êxito conhecido. Nem com ele fará duplo emprego. Enquanto a especialização visa ainda à formação profissional, o pós-graduação se destina ao preparo do futuro corpo docente desta Academia e de outras Faculdades, assim como à formação dos cientistas do direito.

"É claro que estes novos programas reclamam novos métodos de trabalho. Já findou a época em que as cátedras se isolavam. $O$ ensino atual exige $o$ trabalho interdisciplinar, a colaboração de vários mestres, de vários departamentos. Pede até que várias unidades da Universidade sejam chamadas a colaborar em empreendimentos comuns.

“Ora, toda essa nobre missão a Academia não poderá realizar sozinha e isolada. Isso apenas será possivel, se integrada na Universidade. Participando da vida desta, recebendo desta o apoio necessário, poderá a Faculdade realizar suas tarefas, mantendo-se digna de seu passado, nas condições do presente.

“A Academia do Largo de São Francisco orgulha-se de estar vinculada à Universidade de São Paulo. É esta um dos mais notáveis centros de saber do mundo. E é ela também o resultado do esforço e da colaboração de muitos 
mestres desta Casa, que ou a dirigiram com saber, ou com ela colaboraram com desvelo.

"Está convicta, por outro lado, a Academia de que a Universidade dela se orgulha e a compreende. Velha por seu longo passado e por suas nobres tradições que a prendem ao Largo de São Francisco, a Faculdade não pode abandonar o ninho antigo. Nada a impede, porém, de sem deixar o velho, ocupar também outro pouso, que lhe sirva para vôos novos e mais altos.

“色 preciso não olvidar, enfim, que a Faculdade do Largo de São Francisco não é apenas uma escola de direito, é uma escola de política, no alto sentido do termo. Ela não descurará dessa tarefa que, hoje, é imperiosa. A Revolução de 1964, para alcançar seus objetivos políticos democráticos, espera o surgimento de uma elite civil, como a que consolidou a República. Ora, esta elite, Prudente, Campos Sales, Rodrigues Alves, Afonso Pena, Rui Barbosa, toda ela se formou nas Arcadas. Daqui haverá de sair outra, imbuída de patriotismo, formada no amor à liberdade, na dedicação à Justiça que erguerá as novas instituições da democracia brasileira.

"Meus senhores, meus estudantes.

"Nada se constrói sem a mocidade. Muito menos numa escola. Não é isso reverência ao "poder jovem". t' expressão da verdade. Quase se poderia dizer que a Academia é um pouco mais o corpo discente que o corpo docente. Esta é a cabeça, mas aquele é o coração. A vida da Faculdade, portanto, depende do estudante.

"Ora, o acadêmico do Largo de São Francisco é digno da Faculdade em que estuda. Cônscio das tradições que importa preservar, das responsabilidades que as mesmas lhe acarretam, não ignora que é na ordem e pelo trabalho que se progride. Renuncia às facilidades, dispõe-se a sacrifícios, aceita reformas que, necessárias e desejadas, embora lhe imponham maior esforço, melhor o preparam 
para a construção do futuro. Porque quer o melhor, estuda Direito no Largo de São Francisco. E por isso a Academia não envelhece.

"A velha Faculdade, para continuar sempre nova, confia nos seus alunos. Ela ouve ainda o poeta:

"....crê no porvir, na mocidade, Sol brilhante no céu da liberdade!" 